\title{
The globalizability of temporal discounting
}

Kai Ruggeri*, Amma Panin, ... **, \& Eduardo Garcia-Garzon

**All 169 authors listed on page 2

5

10

15

20

25

30

Global choice patterns (lay abstract)

Economic inequality aggravates long-term decision-making, which can perpetuate financial risks. However, inconsistent temporal choices exist globally, so their negative impacts may be more a matter of wealth and environment than differences in decisionmaking. Over 160 collaborators studied choice preferences of 13,629 individuals from 61 countries, focusing on intertemporal choice and financial circumstances. The team finds remarkable persistence of choice anomalies around the world, with most effects explained by inflation, wealth, inequality, and individual differences.

\section{Technical Abstract}

Economic inequality is associated with extreme rates of temporal discounting, which is a behavioral pattern where individuals choose smaller, immediate financial gains over larger, delayed gains. Such patterns may feed into rising global inequality, yet it is unclear if they are a function of choice preferences or norms, or rather absence of sufficient resources to meet immediate needs. It is also not clear if these reflect true differences in choice patterns between income groups. We test temporal discounting and five intertemporal choice anomalies using local currencies and value standards in 61 countries. Across a diverse sample of 13,629 participants, we found highly consistent rates choice anomalies. Individuals with lower incomes were not significantly different, but economic inequality and broader financial circumstances impact population choice patterns.

*Corresponding author: Kai Ruggeri, Columbia University, Mailman School of Public Health, Department of Health Policy and Management, 722 W $168^{\text {th }}$ Street, New York, NY, 10032,

35 USA: kairuggeri@,columbia.edu

AUTHOR NOTE: Supplemental files mentioned in this manuscript will be posted later. 


\begin{tabular}{|c|c|c|c|}
\hline Kai Ruggeri* & Tatianna Dugue & Žan Lep & Rand Said \\
\hline Amma Panin & Twinkle Dwarkanath & Xiang Li & Inés Sanguino \\
\hline Milica Vdovic & Esther Awazzi Envuladu & Samuel Lins & Ahmet Kerem Sarikaya \\
\hline Bojana Većkalov & Nikola Erceg & Ingvild Sandø Lofthus & Nicolas Say \\
\hline Nazeer Abdul-Salaam & Celia Esteban-Serna & Lucía Macchia & Jakob Schuck \\
\hline Jascha Achterberg & Eman Farahat & Salomé Mamede & Mary Shiels \\
\hline Carla Akil & Mareyba Fawad & Metasebiya Ayele Mamo & Yarden Shir \\
\hline Jolly Amatya & Muhammad Fedryansyah & Laura Maratkyzy & Elisabeth D. C. Sievert \\
\hline Kanchan Amatya & David Feng & Silvana Mareva & Irina Soboleva \\
\hline Thomas Lind Andersen & Silvia Filippi & Shivika Marwaha & Tina Solomonia \\
\hline Sibele D. Aquino & Matías A. Fonollá & Lucy McGill & Siddhant Soni \\
\hline Arjoon Arunasalam & René Freichel & Sharon McParland & \\
\hline Sarah Ashcroft-Jones & Lucia Freira & Anișoara Melnic & Federica Stablum \\
\hline Adrian Dahl Askelund & Maja Friedemann & Sebastian A. Meyer & Felicia T. A. Sundström \\
\hline Nélida Ayacaxli & Ziwei Gao & Szymon Mizak & Xintong Tang \\
\hline Aseman Bagheri Sheshdeh & Sandra J. Geiger & Amina Mohammed & Felice Tavera \\
\hline Alexander Bailey & Leya George & Aizhan Mukhyshbayeva & Jacqueline Taylor \\
\hline Paula Barea Arroyo & Iulia Grabovski & Joaquin Navajas & Anna-Lena Tebbe \\
\hline Genaro Basulto Mejía & Aleksandra Gracheva & Dragana Neshevska & Katrine Krabbe Thommesen \\
\hline Martina Benvenuti & Anastasia Gracheva & Shehrbano Jamali Niazi & Juliette Tobias-Webb \\
\hline Mari Louise Berge & Ali Hajian & Ana Elsa Nieto Nieves & Anna Louise Todsen \\
\hline Aliya Bermaganbet & Nida Hasan & Franziska Nippold & Filippo Toscano \\
\hline Katherine Bibilouri & Marlene Hecht & Julia Oberschulte & Tran Tran \\
\hline Ludvig Daae Bjørndal & Xinyi Hong & Thiago Otto & Jason Trinh \\
\hline Sabrina Black & Barbora Hubená & Riinu Pae & Alice Turati \\
\hline Johanna K. Blomster Lyshol & Alexander G. F. Ikonomeas & Tsvetelina Panchelieva & Kohei Ueda \\
\hline Tymofii Brik & Sandra Ilić & Sun Young Park & Martina Vacondio \\
\hline Eike Kofi Buabang & David Izydorczyk & Daria Stefania Pascu & Volodymyr Vakhitov \\
\hline Matthias Burghart & Lea Jakob & Irena Pavlović & Adrianna J. Valencia \\
\hline Aslı Bursalığlu & Margo Janssens & Marija B. Petrović & Chiara Van Reyn \\
\hline Naos Mesfin Buzay & Hannes Jarke & Dora Popović & Tina A.G. Venema \\
\hline Martin Čadek & Ondřej Kácha & Gerhard M. Prinz & Sanne Verra \\
\hline Nathalia Melo de Carvalho & Kalina Nikolova Kalinova & Nikolay R. Rachev & Jáchym Vintr \\
\hline Ana-Maria Cazan & Forget Mingiri Kapingura & Pika Ranc & Marek A. Vranka \\
\hline Melis Çetinçelik & Ralitsa Karakasheva & Josip Razum & Lisa Wagner \\
\hline Valentino E. Chai & David Oliver Kasdan & Christina Eun Rho & Xue Wu \\
\hline Patricia Chen & Peggah Khorrami & Leonore Riitsalu & Ke Ying Xing \\
\hline Shiyi Chen & Jakub M. Krawiec & Federica Rocca & Kailin Xu \\
\hline Georgia Clay & Nato Lagidze & R. Shayna Rosenbaum & Sonya $\mathrm{Xu}$ \\
\hline Simone D'Ambrogio & Aleksandra Lazarević & James Rujimora & Yuki Yamada \\
\hline Kaja Damnjanović & Aleksandra Lazić & Binahayati Rusyidi & Aleksandra Yosifova \\
\hline Grace Duffy & Hyung Seo Lee & Charlotte Rutherford & Zorana Zupan \\
\hline
\end{tabular}




\section{Introduction}

Effective financial choices over time are essential for securing financial well-being $(1,2)$, yet individuals often prefer immediate gains at the expense of future outcomes $(3,4)$. This tendency,

5 known as temporal discounting (5), is routinely associated with lower wealth (6-13), which is especially concerning given incongruent impacts on economic inequality brought about by the COVID-19 pandemic (14). Contrasting most discounting research, our study involves a series of intertemporal choice anomalies (15) identified in WEIRD labs, including patterns which choice models often ignore. Addressing both the depth of the method used and concerns about the

10 generalizability of behavioral research (10), this richer perspective of intertemporal decision-making in a global sample assesses the presence and prevalence of anomalies in local contexts. We also focus on the influence of economic inequality to determine if low-income individuals are somehow more extreme decision-makers, or if environment, moreso than simply individual circumstances, is a more impactful factor across populations.

\section{Hypotheses}

Inequality and low incomes have routinely been associated with greater discounting of future outcomes $(12,17,18)$. We expected to find temporal discounting - to varying degrees - in populations around the world. However, we also expected that prevailing interpretations (i.e., that lower-income individuals show more extreme discounting) result from narrow measurement

20 approaches. With broader testing of more anomalies, rather than being limited to indifference points (a threshold value for preferring now versus later), we expected more robust conclusions about choice patterns. The most comprehensive related study found lower-income countries had lower trust in systems, which led to the steepest rates of discounting (i.e., the threshold for giving up an immediate gain for a later, larger one was much higher) $(7,19)$. This is valuable but does not

25 necessarily mean that lower-income populations are actually unique decision-makers, as the indifference point was the primary indicator. To account for this, we used similar methods but tested multiple intertemporal choice domains, allowing rates of certain anomalies to be considered along with specific value thresholds.

Inflation, which tends to be higher in lower-income countries (20), is associated with stronger 30 preferences for immediate gains $(21,22)$. We expected to confirm this pattern, which would indicate that such preferences may be more related to increased probability that any future gains will be worth substantially below their current value than to individual income or wealth. We limited our hypotheses to inflation versus extreme inflation: we expected differences in preferences would emerge only at substantially larger inflation rates (over 10\%) and hyperinflation (over 50\%), and less so between regions with varied but less extreme differences (significantly below 10\%).

To test these hypotheses, we used four choice anomalies outlined in one of the most influential articles(23) on intertemporal choice: absolute magnitude, gain-loss asymmetry, delay-speedup asymmetry, and common difference (we refer to this as present bias, which is the more common term), plus a fifth, subadditivity, to complete three time intervals(24). By testing multiple anomalies with a simplified indifference measure (derived from the first set of choices), the prevalence of each 
anomaly provides a more robust determination of the generalizability of the construct than an indifference point alone.

\section{Measurement}

Most research on temporal preferences uses indifference points (25), which determine the threshold at which individuals will shift from immediate to delay (and vice-versa). Data from that approach are robust, and converge on an inverse relationship between income/wealth and discounting rate. However, multiple binary choice comparisons are ideal for demonstrating multidimensional choice patterns, such as is found with prospect theory, expected utility, and other choice paradoxes or cognitive biases. They are also better suited for testing in multiple countries $(26,27)$ when multiple small adaptations to values in different currencies are necessary. Taking this into consideration, our method leveraged one of the most widely cited papers on decision-making (23), which proposed four critical intertemporal choice anomalies. Yet, while studies of individual anomalies exist from various regions $(28-30)$ no comprehensive nor multi-country study has simultaneously assessed the generalizability of all four:

Absolute magnitude: Increased preference for delayed gains when values become substantially larger, even when relative differences are constant (e.g., prefer $\$ 500$ now over $\$ 550$ in 12 months and prefer $\$ 5500$ in 12 months over $\$ 5000$ now $(4, \sigma))$.

Gain-loss asymmetry: Gains are discounted more than losses, though differences (real and relative) are constant (e.g., prefer to receive $\$ 500$ now over $\$ 550$ in 12 months, but also prefer to pay $\$ 500$ now overpaying $\$ 550$ in 12 months).

Delay-speedup asymmetry: Accepting an immediate, smaller gain if the delay is framed as added value, but preferring the larger, later amount if an immediate gain is framed as a reduction (e.g., prefer to receive a gain of $\$ 500$ rather than wait 12 months for an additional $\$ 50$ and prefer to wait for 12 months to receive $\$ 550$ rather than to pay $\$ 50$ and receive the gain now).

Present bias: Lower discounting over a given time interval when the start of the interval is shifted to the future (e.g., prefer $\$ 500$ now over $\$ 550$ in 12 months and prefer $\$ 550$ in two years over $\$ 500$ in 12 months).

We also assess subadditivity (24) effects, which adds an interval of immediate to 24 months, thereby allowing us to assess discounting over three time intervals (0-12 months, 12-24, and 0-24) completely(31). Subadditivity is considered present if discounting is higher for the two 12-month intervals compared to the 24-month interval.

All data were collected independent of any other study or source, with a 30-item instrument developed specifically for assessing a base discounting level and then the five anomalies. To validate the metric, a three-country pilot study (Australia, Canada, USA) was conducted to confirm the method elicited variability in choice preferences. We did not assess what specific patterns of potential anomalies emerged to avoid biasing methods or decisions related to currency adaptations. 
For the full study, all participants begin with choosing between approximately $10 \%$ of the national household income average (either median or mean, depending on the local standard) immediately, or $110 \%$ of that value in 12 months. For US participants, this translated into $\$ 500$ immediately or $\$ 550$ in one year. Participants who chose the immediate option are shown the same option set, but the

5 delayed value is now $120 \%$ (\$600). If they continue to prefer the immediate option, a final option offers 150\% (\$750) as the delayed reward. If participants choose the delayed option initially, subsequent choices are 102\% (\$510) and 101\% (\$505). This progression is then inverted for losses, with the identical values presented as payments, increasing for choosing delayed and decreasing for choosing immediate. Finally, the original gain set is repeated using 100\% of the average monthly income to represent higher magnitude choices (table S1).

Following baseline scenarios, subsequent anomaly scenarios incorporated the simplified indifference point, which was the largest value at which participants chose the delayed option in the baseline items. Finally, participants answered ten questions on financial circumstances, (simplified) risk preference, economic outlook, and demographics. Participants could choose between the local official language (or languages) and English. By completion, 61 countries (representing approximately $76 \%$ of the world population) participated (table S2-S3).

We assessed temporal choice patterns in three ways. First, we used the three baseline scenarios to determine preferences for immediate or delayed gains (at two magnitudes) and losses (one). Secondly, for each anomaly scenario, we calculated proportions of participants who exhibited the 20 theoretically described anomaly (table S4). We also calculated proportions of participants who exhibited inconsistent decisions even if not specifically aligned with one of the defined anomalies. Finally, we computed a discounting score based on responses to all choice items, which ranged from 0 (always prefer delayed gains or earlier losses) to 19 (always prefer immediate gains or delayed losses). The score then represents the consistency of discounting behaviors, irrespective of the

25 presence of other choice anomalies.

To explore individual and country-level differences, we performed a series of multilevel linear and generalized (binomial) mixed models that predicted standardized temporal discounting scores and anomalies, respectively. We ran a set of increasingly complex models, including inequality indicators, while controlling for individual debt and assets, age, education, employment, log per-capita GDP and inflation at individual and country-level. Because the raw scores (0-19) have no standard to compare against, we primarily used standardized scores (mean 0 and standard deviation of 1 ) for analysis and visualization.

We detected several relevant non-linear effects (debt, financial assets, and inflation; table S5-S7), which we incorporated into our final models via splines (32). We estimated our results using both frequentist (table S7-S9, fig. S1-S2) and Bayesian techniques (table S10-S11), assessing the consistency of the results. We explored support for potential null effects using a variety of Bayesian approaches (table S12). 


\section{Overview of findings and implications}

Across more than 60 countries and 13,000 participants, we find temporal discounting widely present in every location, with varying but robust rates of five intertemporal choice anomalies (see fig. 1). Income, economic inequality, financial wealth, and inflation each demonstrated clear impacts on the 5 shape and magnitude of intertemporal choice patterns. Better financial environments were consistently associated with lower rates of temporal discounting, whereas higher levels of inequality and inflation were associated with higher rates of discounting yet somewhat lower rates of choice anomalies. In other words, as economic environments worsen, there is a stronger and more consistent tendency to discount future values.

10 Differences between locations are evident, though remarkable consistency of variability exists within countries. Such patterns demonstrate that temporal discounting and intertemporal choice anomalies are widely generalizable, and that differences between individuals are wider than differences between countries. Being low-income does not alone appear to produce unstable decision-making; being in a more challenging environment does.

15 The scientific and policy implications from these findings challenge any assumption that low-income individuals are fundamentally more extreme decision-makers. Instead, these data indicate anyone facing a negative financial environment - even with better incomes within that environment - are likely to make decisions that involve immediate clarity over future uncertainty. Likewise, data indicate that all individuals at all income levels in all regions are more likely than not to demonstrate one or more choice anomaly. 


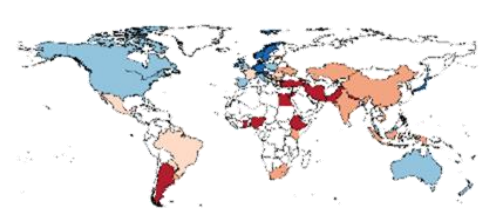

Temporal discount scores

C

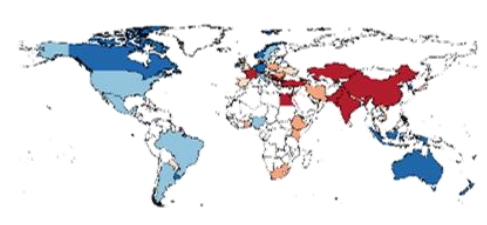

Absolute magnitude

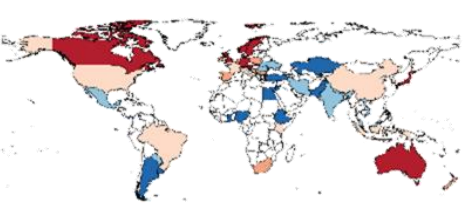

Present bias

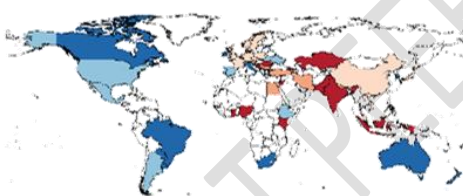

Gain-loss assymetry
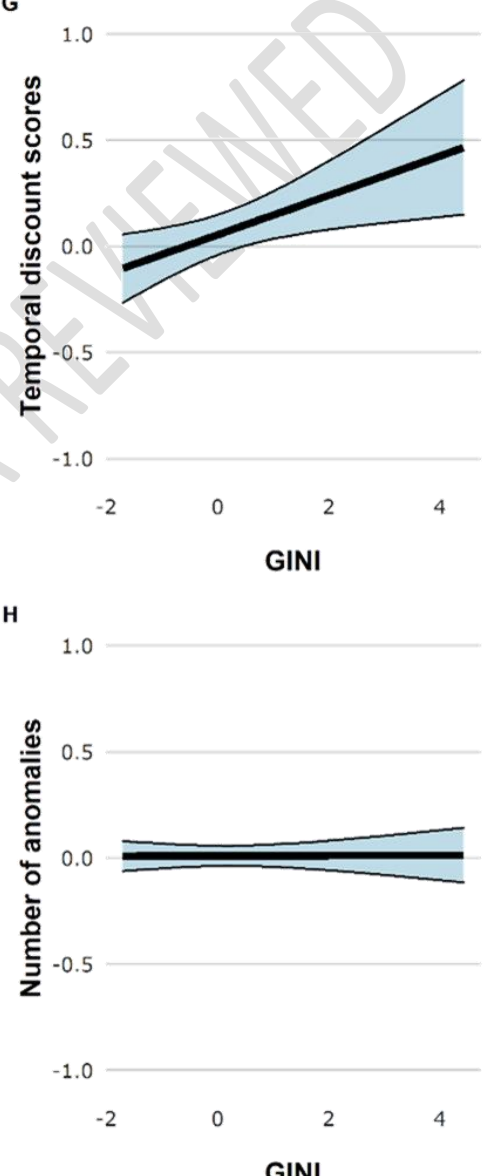

GINI

Fig 1. Global indications of intertemporal choice. Maps of choice preferences in aggregate $(A)$ and by individual anomaly $(B-F)$ indicate heterogeneity in intertemporal choice patterns. While some subtle patterns emerge, particularly stronger preferences for delayed gains in higher-income regions, choice preferences are broadly consistent across 61 countries in the sense that all anomalies appear in all locations. No location consistently presents extremes (high or low) of each 


\section{Detailed analysis of temporal choice anomalies}

We collected 13,629 responses from 61 countries (median sample of 209, tables S2-S3). Though the absolute minimum sample necessary was 30 per country, the sliding scale used for ensuring full power (see SM Selection of countries) started at 120, increasing to 360 for larger countries. Forty-six countries achieved the target sample size, and 56 had at least 120 (with at least 4 countries per continent at 120), thus providing a wide range of economic and cultural environments. Only two countries, where data collection was exceptionally challenging, had below 90 participants, but all locations were still substantially above the absolute minimum. As well as exceeding the minimum sample, we also chose to retain these participants in the analyses as they represent groups often not included in behavioral science $(33,34)$.

In line with related research (7), fig. 2 shows how countries with lower incomes had typically greater temporal discounting levels in the baseline items (table S13). This was most evident in the tendency to prefer immediate gains, even as delayed prospects increased. This pattern was not found for the loss scenario. However, as noted, these items give a useful measure for the indifference level for each individual, but do not give a robust indication of whether temporal choice anomalies are present.

A

20

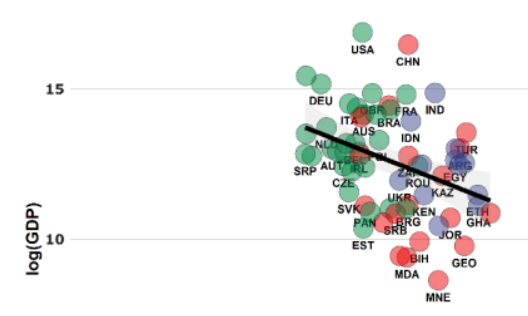

B

20

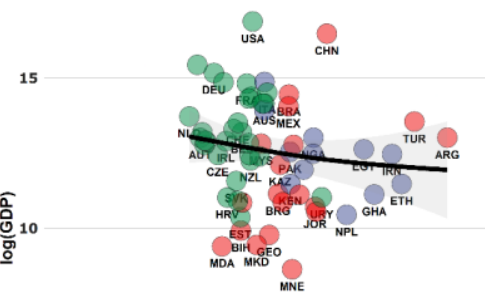

C 20

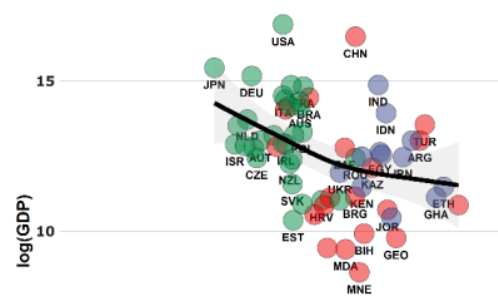

5

o
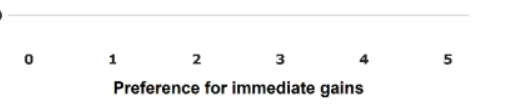

Lower-middle Upper-middle High-income

Fig. 2. Baseline temporal discounting and GDP. There is a clear trend of lower GDP(35) being associated with higher preferences for immediate gains. However, all locations indicate some preference for immediate over delayed. Taken together, this provides support for the hypothesis that baseline temporal discounting is observed globally, and that the economic environment may shape its contours. Results are based on models specified in table S13. 
We employed between-countries random-effect meta-analyses to estimate pooled and unpooled effects for both aggregate scores and individual anomalies (fig. S3-S8). Temporal discounting was present in all countries, with only modest variability for national means (aggregate $M=11.3$, Prediction Interval [7.9- 14.8]; from Japan [M=8.1, $S D=3.9]$ to Argentina [M=15.1, $S D=3.0]$; fig.

5 3). Fifty-four per cent of participants showed at least one anomaly, with 33\% presenting multiple, yet only $2 \%$ showing four (table S14). Anomalies were present in all locations and aggregate values indicated widespread presence of the four primary anomalies (from 13.8\% for absolute magnitude to $40.1 \%$ for gain-loss asymmetry, fig. 3). Gain-loss rates was the most common anomaly in $80.3 \%$ (49) of the countries, with substantially higher rates observed than for other anomalies. While only $10.7 \%$ of the sample engaged in subadditivity behavior (range: 2.7\% [Lebanon] to 20.7\% [New Zealand]), criteria are stricter for this anomaly.

In all cases, significant $Q$-tests and $I^{2}$ values over $70 \%$ suggested that effect size variation at the country level could not be accounted for by sampling variation alone. There were strong relationships between the individual and aggregate scores and some anomalies (i.e., positive for absolute magnitude; negative for present bias and delay-speedup; fig. S9). Additionally, we found a negative effect of GDP on temporal discount scores $(\beta=-0.07,95 \%$ CI $[-0.12,-0.03], \mathrm{p}=0.001)$, and a positive effect for present bias $(\mathrm{OR}=1.09,95 \% \mathrm{CI}[1.03,1.16], \mathrm{p}=0.003)$ and delay-speedup $(\mathrm{OR}=0.95,95 \% \mathrm{CI}[0.91,0.99], \mathrm{p}=0.002)$. We found no effect on the remaining anomalies $(0.95$ $<$ OR $<1.01 ; 0.027<\mathrm{p}<0.688)$. 

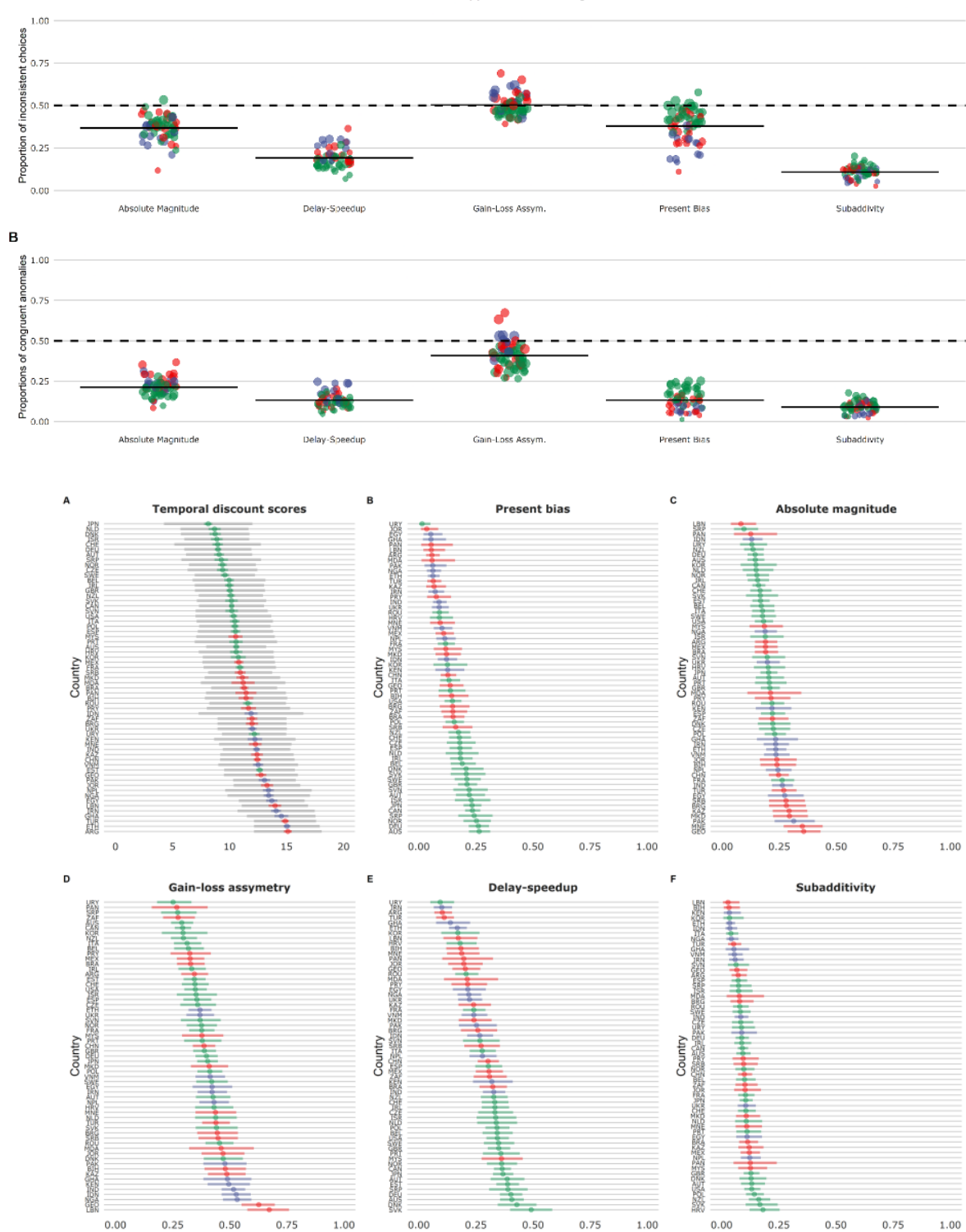

Fig. 3. ABOVE: Proportions of participants that demonstrated inconsistent choice preferences (first row) and proportion of each country sample that aligned with the five anomalies of interest (second row). Apart from absolute magnitude and present bias, no consistent rate based on wealth, and all countries indicate some presence of each anomaly.

BELOW: Each plot presents the distribution of values ordered by mean or proportion value. Plot $A$ presents the distribution of discounting scores by country, including means, prediction intervals (black), and standard deviations (grey) for all countries. Plots B-F show the proportions of participants that presented each anomaly. While difference from lowest to highest for each is noteworthy, similar variabilities exist across all. 
Despite between-country differences in mean scores and anomaly rates, there was substantial overlap between response distributions. Accordingly, results from multilevel models indicated that no more than $20 \%$ of variance was ever explained by between-country differences for scores and was between $2 \%$ (absolute magnitude) and $8 \%$ (present bias) for anomalies. Thus, we find temporal discounting to be globally generalizable, robust, and highly consistent (both in line with expectations) (table S6, fig. S10), where within-country differences between individuals are substantially greater than between-country differences. In other words, we find temporal discounting to be a globalizable - though not universal - construct. We also find there is nothing WEIRD about intertemporal choice anomalies.

We defined inequality at the level of country and at the level of the individual. For countries, we used the most recently published GINI coefficients (30). For individuals, we calculated the difference between their reported income and the adjusted net median local (country) income. At the country level, GINI had a positive relationship with temporal discounting scores $(\beta=0.09,95 \%$ CI $[0.02,0.06], \mathrm{p}=0.002$, table S8), yet no such pattern emerged for specific anomalies, as we observed no effect for the remaining cases $(0.92<\mathrm{OR}<1.01 ; 0.023<\mathrm{p}<0.825$, table S8). Individual income inequality did not predict temporal discounting scores $(\beta=-0.01,95 \%$ CI $[-0.03$, $0.001], \mathrm{p}=.121)$ or rates of anomalies $(0.96<\mathrm{OR}<1.04$; $0.0 .045<\mathrm{p}<0.867$, table S8-S9) with the exception of two small effects for present bias (OR $=1.07,95 \%$ CI $[1.03,1.13], p=0.006)$ and absolute magnitude (OR $=0.92,95 \%$ CI $[0.87,0.98], \mathrm{p}=0.006$, table S9).

These patterns, as shown in fig. 4, are largely in line with expectations, indicating that in aggregate, greater inequality is associated with increased rates of discounting. However, as indicated in fig. 3, intertemporal choice anomalies overall are not unique to a specific income level, and, in fact, worse financial circumstances may produce more consistent choice patterns (i.e., fewer anomalies) due to sustained preference for sooner gains. Whether this aligns with arguments that scarcity leads individuals to focus on present challenges is worthy of considerably further exploration (37). It also reiterates that patterns in population (i.e., country) aggregates are not the same as predicting individual choices (38).

We found consistently that greater willingness to delay larger gains tends to be associated with greater wealth (financial assets), except for the extremely wealthy. Temporal discounting scores generally decreased as wealth increased, except for the wealthiest individuals (expected degrees of freedom $(\mathrm{edf})=2.88, \mathrm{p}<.0001$, table S8). We also observed this nonlinear associations for present bias (edf $=1.01, \mathrm{p}<0.0001)$ and absolute-magnitude (edf $=1.96, \mathrm{p}<.0009)$, and the reverse pattern for delay-speedup (edf $=2.78, \mathrm{p}<.0001)$. For gain-loss asymmetry (edf $=0.474, \mathrm{p}=0.144)$ and subadditivity ( $\mathrm{edf}=0.001, \mathrm{p}=0.472$ ), we found no meaningful relationship between assets and the likelihood of observing either (table S9). Higher levels of debt were associated with lower 
discount rates, particularly for people with lower to medium debt (edf $=2.91, \mathrm{p}<.0001$ ), though debt had no effect on the likelihood of engaging in any specific anomaly $(0.95<$ OR $<1.01 ; 0.035<$ $\mathrm{p}<0.944$, table S9).
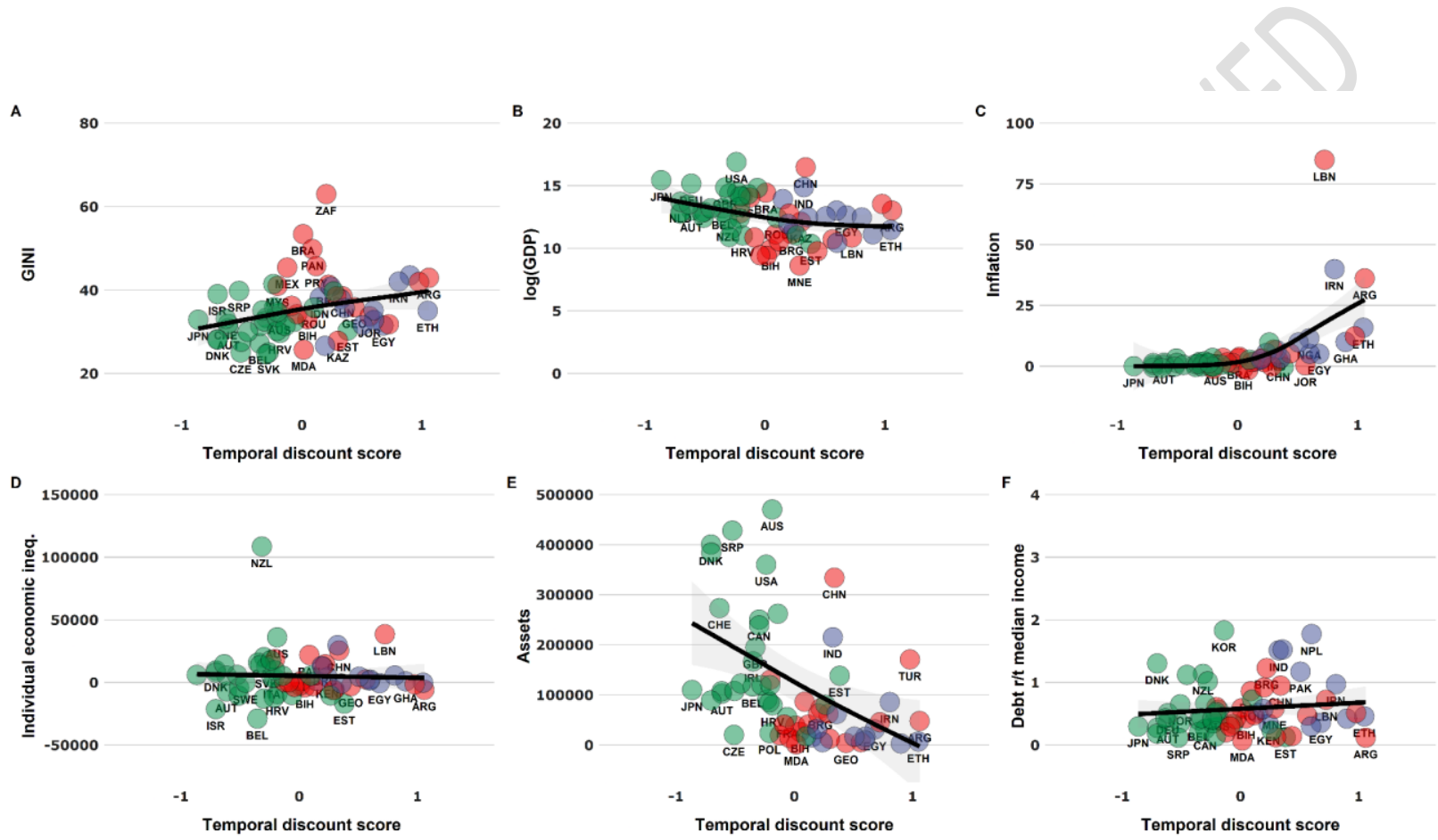

Lower-middle Upper-middle High-income

Fig. 4. Wealth, debt, inequality, and temporal discounting. Plots using standardized scores for temporal discounting indicate an overall trend of greater wealth and income at individual and national level are associated with lower overall temporal discounting, with greater economic inequality and individual debt associated with lower overall temporal discounting. Inflation has a modest relationship with discounting, which becomes much stronger at substantially bigh levels of inflation. Results of GDP on scores and anomalies are from models specified in table S15.

\section{Inflation}

We observed strong relationships between inflation rates and temporal discounting scores as well as all anomalies. There was a particularly strong effect of hyperinflation on temporal discounting (edf = $1.81, \mathrm{p}<.0001$, table S7, fig. S1), with some leveling out at the extremes. Countries experiencing 
severe hyperinflation demonstrate extreme discounts only for gains but not for payments, which minimizes the effect for total scores. However, if limiting to only gains, the effect remains extreme, as indicated by the two gain scenarios in Fig. 3 .

We observed a reverse trend of higher inflation leading to lower likelihood of engaging in anomalies (table S8, fig. S2), namely for present bias (edf $=1.63, \mathrm{p}<.0001)$, absolute magnitude (edf $=1.92, \mathrm{p}$ $<.0001$ ), delay-speedup ( $\mathrm{edf}=1.75, \mathrm{p}<.0001)$, and subadditivity ( $\mathrm{edf}=1,37, \mathrm{p}=0.0019)$. The only positive (but weaker) effect in the case of anomalies was found for gain-loss asymmetry (edf $=$ 1.675, $\mathrm{p}=0.0051)$.

\section{Concluding remarks}

10 For good reason, psychological theory has come under considerable recent criticism due to a number of failed replications of previously canonical constructs (39). There is also wide support to consider that the absence of testing (or adapting methods to test) across populations limits presumed generalizability of conclusions in the field (16). To the extent it is possible for any behavioral phenomenon, we find temporal discounting and common intertemporal choice

15 anomalies to be globally generalizable. This is largely based on finding remarkable consistency and robustness in patterns of intertemporal choice across 61 countries, with substantially more variability within each country than between their means. We emphasize that while discounting may be stronger in worse financial circumstances, particularly those with poorer economic outlooks, it exists in all locations at measurable levels.

20 We do not imply that temporal discounting or specific intertemporal choice anomalies are universal (i.e., present in all individuals at all times). Instead, findings provide extreme confidence that the constructs tested are robust on a global level. It also disrupts any notion that lower-income individuals are somehow uniquely concerning decision-makers, as negative environments are widely influential.

25 We hope these findings would be taken into consideration in both science and policy. The scope of the work, particularly the diversity of the 13,000 participants across these 61 countries, should encourage more tests of global generalizability of fundamental psychological theory that adapts to local standards and norms. Similarly, policymakers should consider the effects of economic inequality and inflation beyond incomes and growth, and give greater consideration to how they have a direct impact on individual choices for entire populations, impacting long-term well-being. 


\section{References}

1. M. Angrisani, J. Burke, A. Lusardi, G. Mottola, "The Stability and Predictive Power of Financial Literacy: Evidence from Longitudinal Data," Working Paper Series (Working Paper 28125, National Bureau of Economic Research, 2020), , doi:10.3386/w28125.

5 2. J. Haushofer, E. Fehr, On the psychology of poverty. Science. 344, 862-867 (2014).

3. G. B. Chapman, Temporal discounting and utility for health and money. Journal of Experimental Psychology: Learning, Memory, and Cognition. 22, 771-791 (1996).

4. L. Green, J. Myerson, E. Mcfadden, Rate of temporal discounting decreases with amount of reward. Memory \& Cognition. 25, 715-723 (1997).

10 5. T. S. Critchfield, S. H. Kollins, Temporal Discounting: Basic Research and the Analysis of Socially Important Behavior. Journal of Applied Behavior Analysis. 34, 101-122 (2001).

6. L. Green, J. Myerson, D. Lichtman, S. Rosen, A. Fry, Temporal discounting in choice between delayed rewards: The role of age and income. Psychology and Aging. 11, 79-84 (1996).

7. A. Falk, A. Becker, T. Dohmen, B. Enke, D. Huffman, U. Sunde, Global Evidence on Economic Preferences. The Quarterly Journal of Economics. 133, 1645-1692 (2018).

8. M. Adamkovič, M. Martončik, A Review of Consequences of Poverty on Economic DecisionMaking: A Hypothesized Model of a Cognitive Mechanism. Front Psychol. 8, 1784 (2017).

9. J. R. Brown, Z. Ivković, S. Weisbenner, Empirical determinants of intertemporal choice. Journal of Financial Economics. 116, 473-486 (2015).

20 10. A. K. Shah, S. Mullainathan, E. Shafir, Some consequences of having too little. Science. 338, 682-685 (2012).

11. J. Sheehy-Skeffington, J. Rea, "How poverty affects people's decision-making processes" (3234, Joseph Rowntree Foundation and LSE Enterprise, York, 2017), pp. 79.

12. T. Epper, E. Fehr, H. Fehr-Duda, C. T. Kreiner, D. D. Lassen, S. Leth-Petersen, G. N. Rasmussen, Time Discounting and Wealth Inequality. American Economic Review. 110, 1177-1205 (2020).

13. E. C. Lawrance, Poverty and the Rate of Time Preference: Evidence from Panel Data. Journal of Political Economy. 99, 54-77 (1991).

14. A. Deaton, "COVID-19 and Global Income Inequality," Working Paper Series (Working Paper 28392, National Bureau of Economic Research, 2021), , doi:10.3386/w28392.

15. D. Read, M. Scholten, in Economic Psychology (John Wiley \& Sons, Ltd, 2017; https://onlinelibrary.wiley.com/doi/abs/10.1002/9781118926352.ch3), pp. 35-50.

16. T. Yarkoni, The generalizability crisis. Behavioral and Brain Sciences, 1-37 (2020). 
17. R. M. Ludwig, J. C. Flournoy, E. T. Berkman, Inequality in personality and temporal discounting across socioeconomic status? Assessing the evidence. Journal of Research in Personality. 81, 79-87 (2019).

18. K. Ruggeri, T. Folke, Unstandard deviation: The untapped value of positive deviance for reducing inequalities. Perspectives on Psychological Science (forthcoming), , doi:10.31234/osf.io/8wky5.

19. A. Falk, J. Hermle, Relationship of gender differences in preferences to economic development and gender equality. Science. 362, eaas9899 (2018).

20. J. Ha, A. Ivanova, P. Montiel, P. Pedroni, "Inflation in Low-Income Countries" (World Bank, 2019), (available at https://elibrary.worldbank.org/doi/pdf/10.1596/1813-9450-8934).

21. L. Gong, Endogenous Time Preference, Inflation, and Capital Accumulation. J. Econ. 87, 241255 (2006).

22. L. R. de Mello Jr., F. G. Carneiro, Consumption behaviour and persistently high inflation: evidence from Latin America. Rev. Bras. Econ. 54, 227-246 (2000).

15 23. G. Loewenstein, D. Prelec, Anomalies in Intertemporal Choice: Evidence and an Interpretation. The Quarterly Journal of Economics. 107, 573-597 (1992).

24. D. Read, Is Time-Discounting Hyperbolic or Subadditive? Journal of Risk and Uncertainty. 23, 532 (2001).

25. A. G. Basile, M. E. Toplak, Four converging measures of temporal discounting and their relationships with intelligence, executive functions, thinking dispositions, and behavioral outcomes. Frontiers in Psychology. 6, 728 (2015).

26. L. Macchia, A. C. Plagnol, S. Reimers, Does experience with high inflation affect intertemporal decision making? Sensitivity to inflation rates in Argentine and british delay discounting choices. Journal of Behavioral and Experimental Economics. 75, 76-83 (2018).

25 27. K. Ruggeri, S. Alí, M. L. Berge, G. Bertoldo, L. D. Bjørndal, A. Cortijos-Bernabeu, C. Davison, E. Demić, C. Esteban-Serna, M. Friedemann, S. P. Gibson, H. Jarke, R. Karakasheva, P. R. Khorrami, J. Kveder, T. L. Andersen, I. S. Lofthus, L. McGill, A. E. Nieto, J. Pérez, S. K. Quail, C. Rutherford, F. L. Tavera, N. Tomat, C. V. Reyn, B. Većkalov, K. Wang, A. Yosifova, F. Papa, E. Rubaltelli, S. van der Linden, T. Folke, Replicating patterns of prospect theory for decision under risk. Nat Hum Behav. 4, 622-633 (2020).

28. S. Clot, C. Y. Stanton, Present bias predicts participation in payments for environmental services: Evidence from a behavioral experiment in Uganda. Ecological Economics. 108, 162-170 (2014).

29. J. E. Blumenstock, M. Callen, T. Ghani, "Mobile-Izing Savings with Automatic Contributions: Experimental Evidence on Present Bias and Default Effects in Afghanistan" (SSRN Scholarly Paper ID 2814075, Social Science Research Network, Rochester, NY, 2016), (available at https:/ / papers.ssrn.com/abstract=2814075). 
30. M. H. Ebrahimi Sarv Olia, M. J. Salimi, G. Bolo, H. Ghouchifard, Sign Effect, Speedup Delay Asymmetry and Gender Effect In the Tehran Stock Exchange. International Journal of Finance \& Managerial Accounting. 5, 41-53 (2020).

31. M. Scholten, D. Read, A. Sanborn, Weighing Outcomes by Time or Against Time? Evaluation Rules in Intertemporal Choice. Cognitive Science. 38, 399-438 (2014).

32. E. J. Pedersen, D. L. Miller, G. L. Simpson, N. Ross, Hierarchical generalized additive models in ecology: an introduction with mgcv. PeerJ. 7, e6876 (2019).

33. M. Urassa, D. W. Lawson, J. Wamoyi, E. Gurmu, M. A. Gibson, P. Madhivanan, C. Placek, Cross-cultural research must prioritize equitable collaboration. Nat Hum Behav. 5, 668-671 (2021).

34. H. IJzerman, N. Dutra, M. Silan, A. Adetula, D. M. B. Brown, and P. Forscher, Psychological Science Needs the Entire Globe. APS Observer. 34 (2021) (available at https://www.psychologicalscience.org/observer/global-psych-science).

35. World Bank Country and Lending Groups - World Bank Data Help Desk, (available at https://datahelpdesk.worldbank.org/knowledgebase/articles/906519-world-bank-countryand-lending-groups).

36. Gini index (World Bank estimate) | Data, (available at https://data.worldbank.org/indicator/SI.POV.GINI).

37. A. K. Shah, S. Mullainathan, E. Shafir, An exercise in self-replication: Replicating Shah, Mullainathan, and Shafir (2012). Journal of Economic Psychology. 75, 102127 (2019).

38. D. A. Hensher, L. W. Johnson, Applied Discrete-Choice Modelling (Routledge, 2018).

39. C. F. Camerer, A. Dreber, E. Forsell, T.-H. Ho, J. Huber, M. Johannesson, M. Kirchler, J. Almenberg, A. Altmejd, T. Chan, E. Heikensten, F. Holzmeister, T. Imai, S. Isaksson, G. Nave, T. Pfeiffer, M. Razen, H. Wu, Evaluating replicability of laboratory experiments in economics. Science. 351, 1433-1436 (2016). 
Acknowledgements: The authors wish to thank the Columbia University Office for Undergraduate Global Engagement. We also thank Lindokuhle Njozela.

Funding: The authors received no specific funding for this research. A small amount of discretionary funding provided by the PI's institution paid for pilot study participants and for

5 honoraria to organizations that assisted with data collection in several locations. These were provided by Columbia University Undergraduate Global Engagement and the Department of Health Policy and Management. No other funding was provided; all collaborators did so in a voluntary capacity.

\section{Author contributions:}

Project coordination and administration: KR, TD

Supervision: KR, JKBL, MF, PK, JR, CES, LW, ZZ

Writing: KR, EGG, AP, SR, IS

Competing interests: Authors declare that they have no competing interests.

Data and materials availability: All data, code, and materials used in this study will be available at 